\title{
Scaled Rocket Testing in Hypersonic Flow
}

\author{
Aaron Dufrene*, Matthew MacLean ${ }^{\dagger}$, Zakary Carr ${ }^{\ddagger}$, Ron Parker ${ }^{\S}$, Michael Holden** \\ CUBRC / LENS, Buffalo, NY, 14225 \\ Manish Mehta ${ }^{\dagger}$ \\ NASA Marshall Space Flight Center, Huntsville, AL 35811
}

\begin{abstract}
NASA's Space Launch System (SLS) uses four clustered liquid rocket engines along with two solid rocket boosters. The interaction between all six rocket exhaust plumes will produce a complex and severe thermal environment in the base of the vehicle. This work focuses on a recent $2 \%$ scale, hot-fire SLS base heating test. These base heating tests are short-duration tests executed with chamber pressures near the full-scale values with gaseous hydrogen/oxygen engines and RSRMV analogous solid propellant motors. The LENS II shock tunnel/Ludwieg tube tunnel was used at or near flight duplicated conditions up to Mach 5. Model development was strongly based on the Space Shuttle base heating tests with several improvements including doubling of the maximum chamber pressures and duplication of freestream conditions. Detailed base heating results are outside of the scope of the current work, rather test methodology and techniques are presented along with broader applicability toward scaled rocket testing in supersonic and hypersonic flow.
\end{abstract}

\section{Introduction}

$\mathrm{R}$ eusable solid rocket motors and hydrogen/oxygen rocket engines have been developed for subscale supersonic and hypersonic wind tunnel tests of NASA's Space Launch System (SLS) vehicle in the LENS II shock/Ludwieg tube facility. SLS is composed of four RS-25D LOX/LH2 rocket engines in the core stage and two 5 -segment solid rocket motors in the booster stage. SLS is designed to take NASA beyond low-earth-orbit for the first time in over forty years and the geometry and rocket motors are significantly different that previously flown systems. Convective base heating testing is one of a series of ground tests required to successfully develop this next generation rocket. Rocket motor plume interaction drives base heating at higher altitudes and Mach numbers[1] and is extremely complex and difficult to simulate accurately with modern computational fluid dynamic tools. Ground experiments of a $2 \%$ scale model operating near flight-scale pressures with flight-like propellant at duplicated flight conditions have been tested in the LENS II facility. These tests will help define ascent plume induced thermal design environments for the SLS vehicle. A photograph of the $2 \%$ base heating model is shown in Figure 1.

Scaled rocket testing in hypersonic flow has been used historically for plume characterization and base flow characterization. Other applications could utilize the same facilities and test techniques to study steady and unsteady force measurements, dynamic events, retro-propulsion, and acoustic or vibration characterization. These studies focus on base flow characterization, and Figure 2 (reproduced from Ref. [2]) shows the complex nature of base flow physics with plume interactions. Assuming geometric similitude can be maintained through scaling, several other parameters must be considered including, but not limited to, rocket chamber chemistry, pressure and temperature, and freestream pressure, temperature, Mach number, and dynamic pressure. Numerous references discuss the merits of various scaling parameters including Refs. [3-8] among others. There is a general consensus that the ratio of chamber pressure to freestream pressure should match flight in order to obtain proper plume characteristic expansion. Scaling freestream conditions in this way results in very low Reynolds number flows over the vehicle

\footnotetext{
* Senior Research Scientist, Member AIAA; dufrene@cubrc.org

$\dagger$ Senior Research Scientist, Member AIAA; maclean@cubrc.org

* Research Scientist, Member AIAA; zakery.carr@cubrc.org

$\S$ Senior Research Scientist, Member AIAA; parker@cubrc.org

** Vice President of Hypersonics, Fellow AIAA; holden@cubrc.org

† Research Scientist, Aerosciences Branch, NASA Marshall Space Flight Center, Huntsville, AL
} 
forebody for small scale sizes, so scaled boundary layer thicknesses will not be preserved. Freestream Reynolds numbers will scale directly with model size, so the larger the scale size the better the match. Plume interactions drive the base flow fluid dynamics at the high altitudes greater than $15 \mathrm{~km}$ considered in this program, so forebody flow and boundary layer thicknesses are considered a second order parameter. Freestream dynamic pressure can influence plume expansion and base flow, but in almost all cases LENS II can duplicate flight velocity and freestream pressure, so dynamic pressure similitude is preserved.

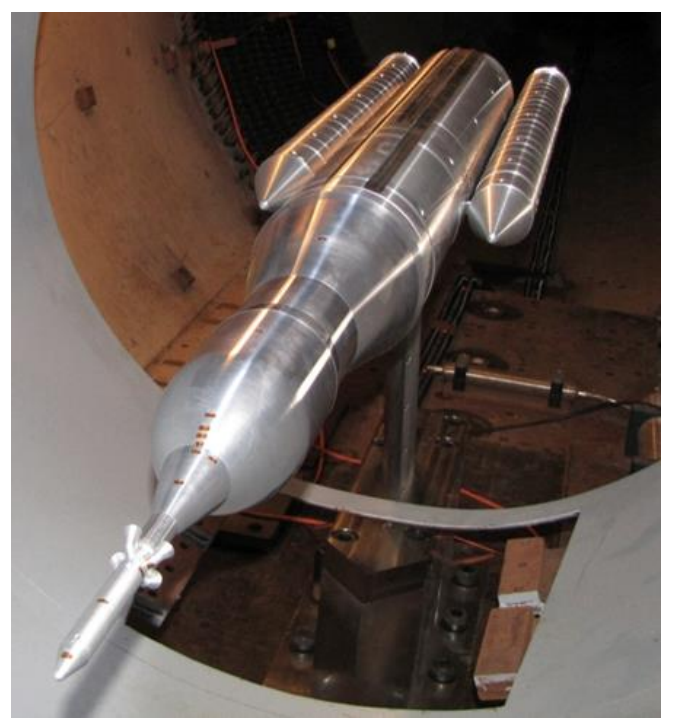

Figure 1. 2\% scale hot-fire SLS model mounted in the LENS II tunnel

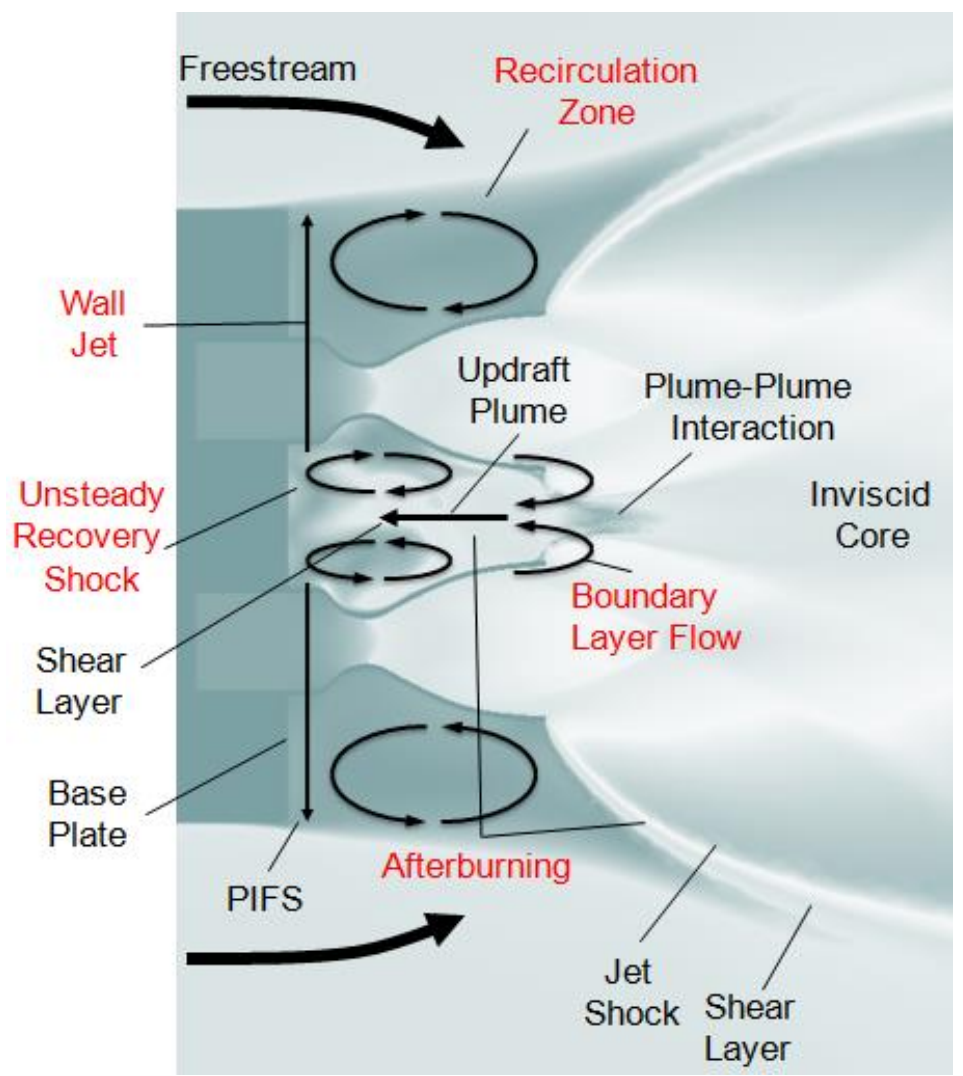

Figure 2. Base Flow Field Fluid Dynamic Structures[2]

American Institute of Aeronautics and Astronautics 


\section{Rocket Motor/Engine Development \& Performance}

The development of scaled solid rocket motor and core-stage engines was based the design of the Space Shuttle base heating model described in Ref. [9]. The Space Shuttle base heating model core stage engine was designed to operate up to half of the full-scale chamber pressures or approximately $1,400 \mathrm{psi}$, and the solid rocket motor pressures were scaled proportionally. SLS subscale rocket motor and engine design targeted chamber pressures approximately twice those operated during the Space Shuttle base heating test. Typical rocket motor gas properties that are relevant to plume interaction scaling are provided below in Table I.[10] Base heating studies require hot-fire motors in order to obtain representative, scalable base heating environments, however, other scaled rocket testing simulation might not require hot-fire engines. For instance, cold hydrogen gas is a fairly good simulant for hot solid rocket motor and kerosene based liquid propulsion systems as far as mass flow, plume velocity \& expansion parameters. Heating inert gases or mixtures of various gases might be appropriate in some cases as well. Good similarity between reaction control engines on the Orion capsule and a hypersonic wind tunnel model with simulated jets was obtained with a warm hydrogen/nitrogen mixture.[11] To minimize scaling issues, engine and motor gas properties were matched by using the same fuels as the full-scale SLS vehicle.

Table I. Gas Properties for Scaled Rocket Engine/Motor Testing or Simulation

\begin{tabular}{|c|c|c|c|c|c|c|c|c|}
\hline & $\begin{array}{c}\text { Warm } \\
\mathrm{CH}_{4} \\
\end{array}$ & $\begin{array}{c}\text { Cold } \\
\mathrm{N}_{2} \\
\end{array}$ & $\begin{array}{c}\text { Cold } \\
\mathrm{He}\end{array}$ & $\begin{array}{c}\text { Cold } \\
\mathbf{H}_{2} \\
\end{array}$ & $\begin{array}{c}\text { Hydrazine } \\
\text { Monopropellant }\end{array}$ & $\begin{array}{l}\text { Solid Rocket } \\
\text { AP/Aluminum }\end{array}$ & $\mathbf{H}_{2} / \mathbf{O}_{2}{ }^{*}$ & RP-1/O ${ }^{*}$ \\
\hline g & 1.3 & 1.4 & 1.67 & 1.4 & 1.34 & 1.21 & 1.26 & 1.24 \\
\hline MW & 16 & 28 & 4 & 2 & 11 & 25 & 14 & 23 \\
\hline $\mathbf{T}(\mathbf{k})$ & 500 & 300 & 300 & 300 & 900 & 3100 & 3500 & 3400 \\
\hline $\mathbf{a}(\mathbf{m} / \mathbf{s})$ & 615 & 353 & 1021 & 1321 & 955 & 1191 & 1618 & 1235 \\
\hline $\mathbf{m}_{-}$dot $^{* * *}$ & 2.08 & 3.90 & 1.61 & 1.04 & \begin{tabular}{|l}
1.38 \\
\end{tabular} & 1.00 & 0.77 & 0.99 \\
\hline \multicolumn{9}{|c|}{ *Typical exhaust properties are taken from Sutton's Rocket Propulsion Elements } \\
\hline
\end{tabular}

Short-duration testing is critical to model and instrument reusability, so test time is long enough to obtain highquality steady measurements, but short enough to ensure reusability of the hardware. A typical timing sequence is shown in Figure 3, showing that the flow over the model starts just prior to, or coincident with, the ignition of the solid rocket motors. Compared to the core stage, the solid rocket motors take longer to start and become steady so the core-stage engine firing is delayed by $10-15 \mathrm{~ms}$. All engines are firing for a steady-state test time of $\sim 40-50 \mathrm{~ms}$, at which point the core-stage engines shut down immediately, and solid rocket motors begin to slowly shut down. Tunnel test time is up to $300 \mathrm{~ms}$ at lower velocity/lower Mach number conditions and as short as $30 \mathrm{~ms}$ at high velocity/Mach number conditions, so repeatable and accurate timing of rocket motors and tunnel operation has been demonstrated and is critical to successful base heating studies.

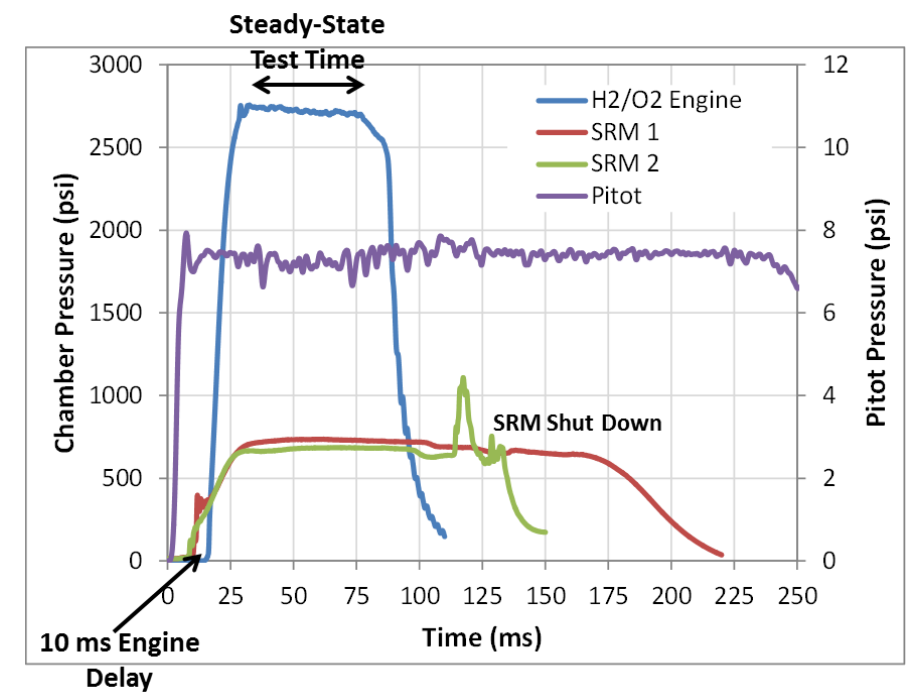

Figure 3. Typical timing sequence for $2 \%$-scale SLS base heating hot-fire testing 
Short-duration testing also has the benefit of allowing very large scale rocket motors to be tested at simulated altitudes or in supersonic and hypersonic freestream conditions. Total mass flow rate through all engines and motors for the SLS base heating test corresponds to $\sim 7 \mathrm{~kg} / \mathrm{s}$ of hot rocket exhaust, however this is only limited by the highpressure pluming or the acceptable rise in ambient pressure during testing. Testing for light weight or high temperature rocket simulations in the LENS II facility which has a vacuum chamber over 300 cubic meters can easily accommodate model mass flow rates of $10-50 \mathrm{~kg} / \mathrm{s}$ depending on test times and conditions. Cold gas simulations with higher molecular weight gases good exceed $300 \mathrm{~kg} / \mathrm{s}$.

Various images or engines/motors firing are shown in Figure 4. Figure 4a\&b shows the full-stack configuration firing with Mach 2.8 external flow at approximately $70 \mathrm{kft}$ and Mach 4 at $100 \mathrm{kft}$, respectively. Figure $4 \mathrm{c}$ shows the core-stage only firing into a simulated altitude of $170 \mathrm{kft}$ with no flow. These three images represent the various types of imaging that was captured throughout the test series. Almost all tests included the use of multiple IR imagers and either high-speed video or high-speed Schlieren,

The four hydrogen/oxygen engines are ported from a central combustor to minimize thrust/pressure mismatches and to simplify the model propulsion system. The central combustor is designed to operate at full-scale pressure up to approximately $2,900 \mathrm{psi}$. Gaseous hydrogen and oxygen charge tubes are pressurized up to 6,000 psi depending on the test conditions. During the test, gases are fed through flow-control venturis that set the O/F ratio to $\sim 6$, and constant pressure is maintained through long, constant-diameter charge tubes. Gas flow is initiated by opening fastresponse balanced poppet solenoid valves and the ignition source is a glow plug. The central combustor reaches steady state engine pressure in less than $20 \mathrm{~ms}$ from sending the valve triggering signal. Specific details of engine performance and development are reported in Ref. [12].

The solid rocket motors use an ammonium perchlorate/high-aluminum-loaded solid propellant grain that is analogous to the RSRMV propellant. Thin cylindrical propellant castings are used to ensure even burning and achieve steady chamber pressures. The ignition source is a hydrogen/oxygen torch that adds less than $2 \%$ water to the combustion products, which is already dominated by water. Other ignition sources did not prove fast enough to get the solid rocket motors up to full, steady pressure within 30ms. These motors operate from 100-720psi. Specific details of motor performance and development are reported in Ref. [13].

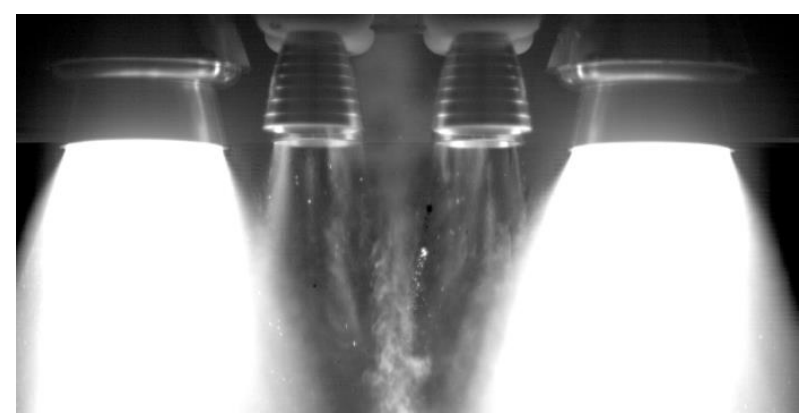

a. Visible camera, top view, $70 \mathrm{kft}$, full-stack

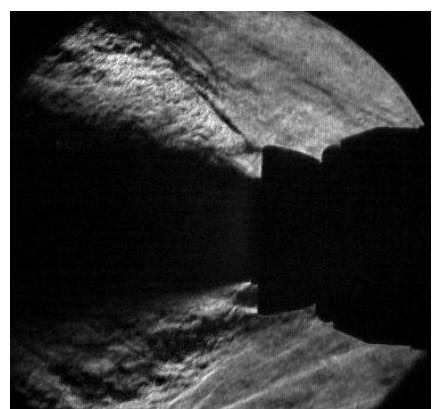

b. Schlieren side view, $100 \mathrm{kft}$, full-stack

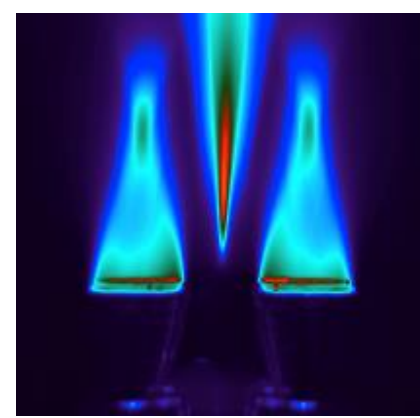

c. Long-wave IR, Top view, 170 kft, Core only

Figure 4. Imaging of $2 \%$-scale SLS hot-fire test at various conditions with full-stack configurations and coreonly configuration

\section{SLS Base Heating Measurements}

The primary goal of the ATA-002 test program is to define the base heating environment. Heat transfer measurement with fast-response thin-film heat transfer gauges or thermocouples is a common, well-understood diagnostic and represents the majority of the measurements in this program. Pressure and radiometer measurements are also made in the base region to help define the surface environments. Scaling 2\%-model-scale heat transfer data to flight is complicated by the fact that gas temperature and gas composition is unknown. Typical aerothermal 
scaling is not difficult, because the tunnel freestream conditions are well defined, but plume interactions are poorly understood. This was a large source of uncertainty for previous Space Shuttle base heating studies[14, 15]. There were two approaches to determine gas temperature in previous testing. The first method relied on platinum-rhodium thin-wire resistance temperature detectors (RTDs)[16]. These are minimally-heated hot-wire probes that heat up when exposed to the rocket exhaust. Gas properties are unknown, so two different length wires and a complex analysis is required to reduce the temperature data. This measurement is intrusive and often had uncertainties of several hundred degrees Rankine. The second method utilized a heated base plate and high-temperature thin-film heat flux instruments[17]. As the wall temperature increases heat transfer decreases linearly to the gas recovery temperature. Therefore, from tests performed with the base plate heated to several different temperatures, gas temperature can be extrapolated. This method is nonintrusive, but has downsides including the need to perform several runs to obtain one gas temperature measurement, and the need to use high-temperature instrumentation which limits the instrumentation options. These measurements require a complex setup, and other parts of the model such as nozzle or central combustor can be inadvertently heated which may affect measured heat transfer. Also, as the wall is heated heat transfer goes down and the signal-to-noise ratio of the heat transfer measurements is reduced.

The importance of this base-gas temperature measurement, and the high uncertainty reported in previous programs motivated the development of an instrument that was based on tunable diode laser absorption spectroscopy (TDLAS) which shows promise as a more accurate, non-intrusive measurement of path-averaged base gas temperature. From TDLAS measurements, time-resolved, path-integrated base-region gas temperature is obtained with information about pressure and tracer species concentration also available. Water is a primary exhaust species in many hot-fire rockets including SLS, and is used as the spectroscopic tracer. The optical paths used during the base heating test series are shown below in Figure 5. Optical fibers with a loss of less than $0.2 \mathrm{~dB} / \mathrm{m}$ at the laser emission wavelength is used to bring the light into and out of the LENS II test section through vacuum-tight feedthroughs. Light from the laser source is coupled into a single-mode fiber using a numerical-aperture-matched reflective collimator. An identical collimator but with a sapphire window to protect the optic is used to pitch the beam over the measurement path. After passing through the measurement region the light is caught by a fibercoupled reflective collimator matched to the numerical aperture of the multimode fiber used to pass the light out of the test section. A ZnSe asphere is used to focus the light from the end of the fiber onto a Kolmar KISDP-1-J1/DC InSb detector with a $15 \mathrm{MHz}$ bandwidth. A high-speed acquisition system acquires approximately $170 \mathrm{~ms}$ of test data at $100 \mathrm{MHz}$. A narrow bandpass filter to eliminate the effect of light emission from the operation of the motors was initially also included in the optical setup but was later determined to be unnecessary. Experimental calibration and early results are reported in Ref. [18].

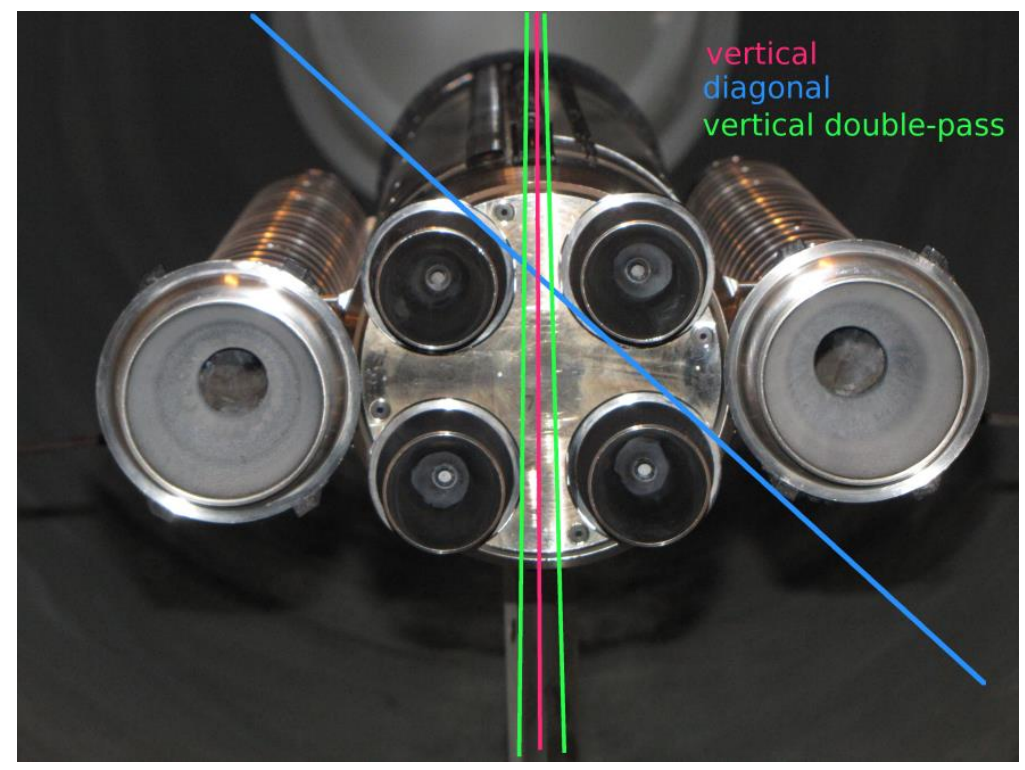

Figure 5. Optical paths used in base-heating temperature measurement. 


\section{Shock \& Ludwieg Tube Testing}

SLS base heating studies are being executed in the LENS II shock and Ludwieg tunnel. Data from this test will assess peak convective heat flux design sensitivity concerns. Testing includes first-stage testing with all four corestage engines and both solid rocket motors as well as second-stage tests post SRB separation with and without tunnel flow. LENS II is capable of operating over a Mach range of $2.7 \leq \mathrm{M}_{\infty} \leq 9.25$ and pressure altitudes of sealevel $\leq \mathrm{H} \leq 200 \mathrm{kft}$ (Figure 6). LENS II can operate as a throatless Ludwieg tube with total temperatures up to 400K at Mach 2.7, standard Ludwieg tube with total temperatures up to 500K from Mach 3.5-7, and flight matching total temperatures up to Mach 8 as a reflected shock tunnel. Base heating test freestream conditions are designed to match flight conditions exactly, as opposed to typical scaled Reynolds number testing. A small correction to freestream pressure is made when operating the engines at less than $100 \%$ of the full-scale value. This is done to preserve the plume expansion and interaction region which has a first-order effect on base heating levels. Model boundary layer conditions do not match flight-scale, but analysis indicates boundary layer state and size are not drivers in base heating levels. Mach number versus Reynolds number plots for all of the LENS reflected shock tunnels is shown in Figure 7. LENS II has a large Reynolds number capability, but all of the base heating tests are towards the lower edge of the orange box that represents LENS II capabilities. Additional LENS II capabilities are described in Figure 8. Dynamic pressure is plotted separately, because this can be an important parameter for scaled rocket testing. All of the base heating studies were tested in the smallest nozzle in either Ludwieg tube mode or reflected shock tunnel mode depending on the required Mach number.

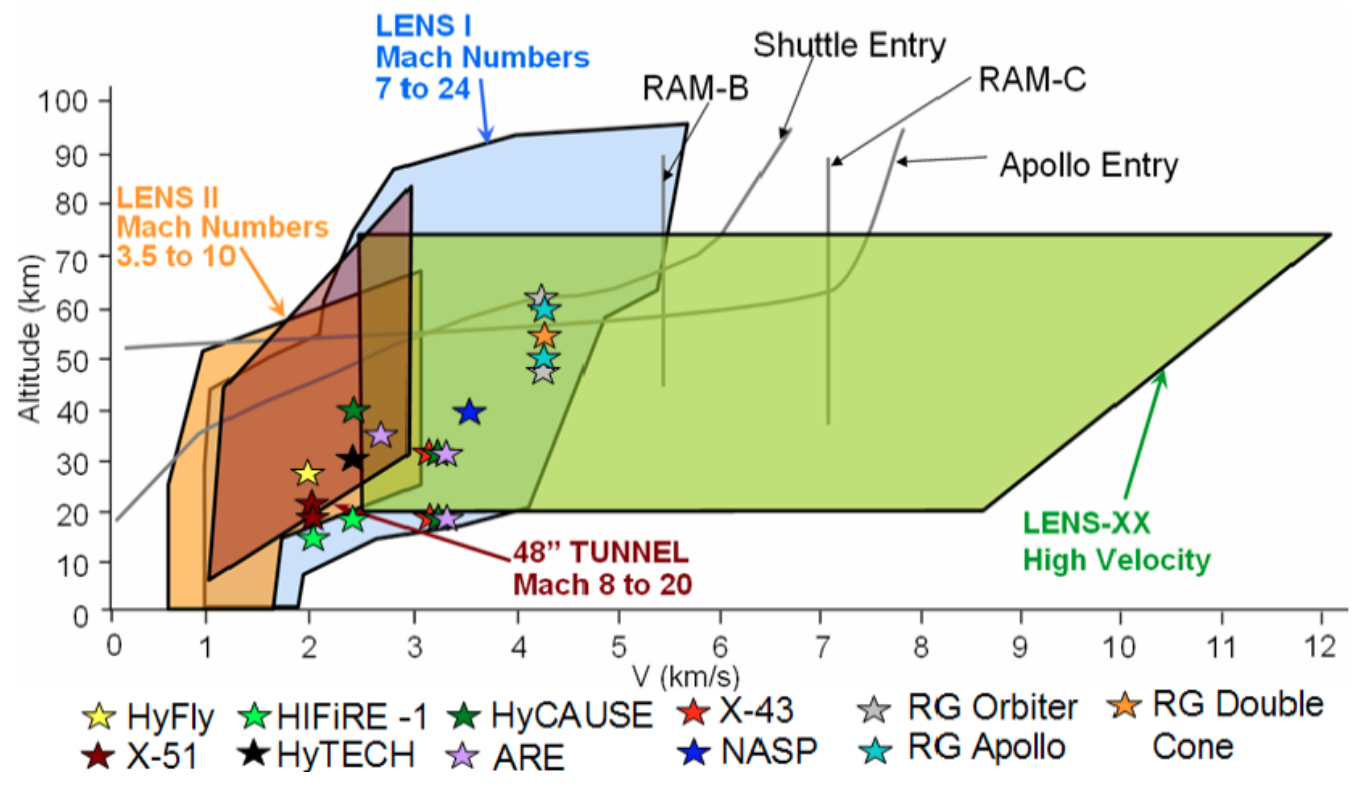

Figure 6. Velocity/Altitude Capabilities of the LENS Shock Tunnels and Expansion Tunnel 


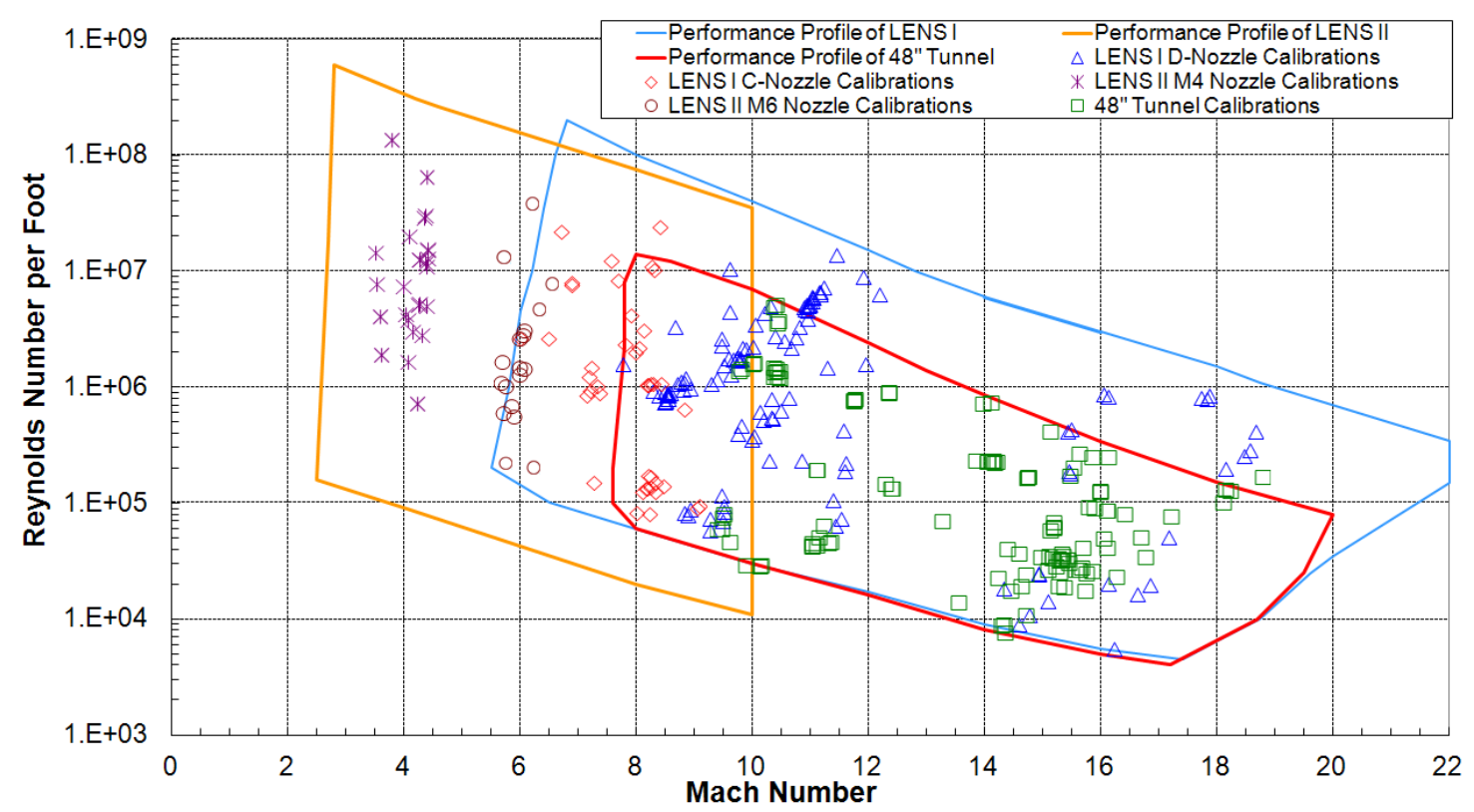

Figure 7. LENS Shock Tunnel Facilities Reynolds Number vs. Mach Number

\begin{tabular}{|l|}
\hline Velocity Range $(\mathrm{km} / \mathrm{s})$ \\
$0.5-3.0$ \\
Altitude $(\mathrm{km})$ \\
$\mathrm{SL}-60$ \\
Reynolds Numbers $(1 / \mathrm{m})$ \\
$10^{5}-10^{9}$ \\
Shock Tunnel Test Time \\
up to $100 \mathrm{~ms}$ \\
Ludwieg Tunnel Test Time \\
up to $320 \mathrm{~ms}$ \\
Mach Numbers \\
Mach $2.5-5(100 \mathrm{~cm}$ Exit) \\
Mach $5-7(150 \mathrm{~cm}$ Exit) \\
Mach $5-10(180 \mathrm{~cm}$ Exit $)$
\end{tabular}

d. LENS II facility capabilities

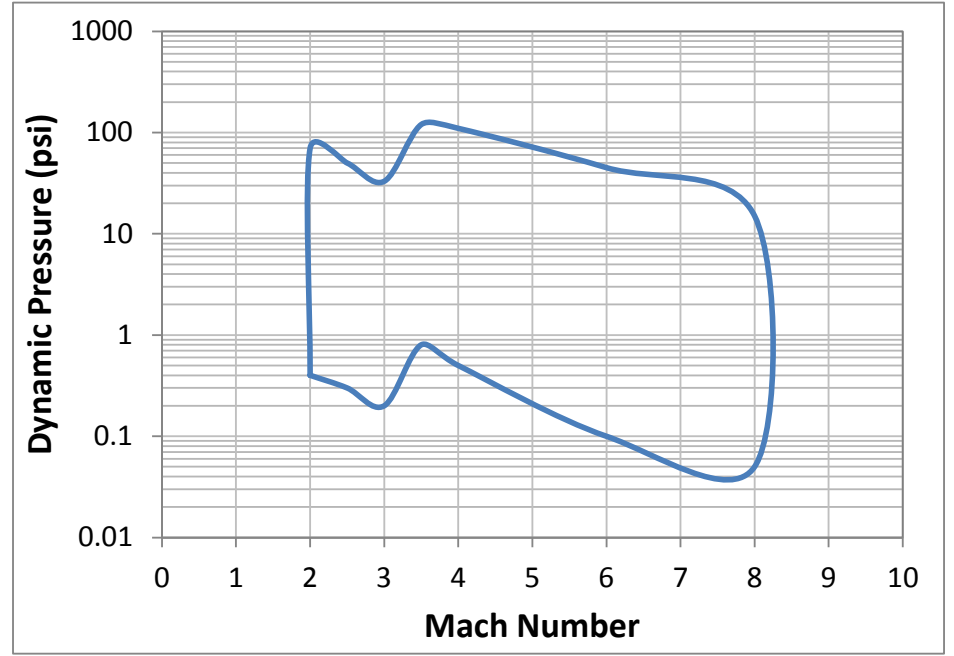

e. Dynamic pressure vs. Mach number

Figure 8. LENS II Shock/Ludwieg Tube Capabilities

Computational fluid dynamic (CFD) analysis was used to support the SLS Base Heating studies in several different ways. CFD simulations were run using NASA's DPLR code[19]. Initially, CFD was used to evaluate scalesize, model placement in the tunnel, angle-of-attack limits, and tunnel wall effects. CFD was also used to design and place the model sting support. Various positions, widths, and fore/aft angles were evaluated. Comparisons of base pressure on a free flying SLS configuration were compared to the various sting mounted designs until the influence of the sting was near negligible. This is an important design feature for base studies that is often ignored. The Space Shuttle base heating Ludwieg tube testing for instance had a sting support that ran most of the length of the external tank and almost as wide as the external tank. The Shuttle itself sits on top of the external tank, so the sting likely has less influence on the orbiter's base, but sting size is still an important consideration. An example of comparisons for the final sting configuration at Mach 2.5 and Mach 5 flow is shown in Figure 9. Results are condensed and summarized for the purposes of this paper. CFD results showed that the sting fore/aft angle is important and needs to be relatively sharp, so a half angle of $15-\mathrm{deg}$ was selected. Sting width was also important, so the minimum 
allowable to support high-pressure tubing, instrument and control wires at $3.8 \mathrm{~cm}$. was selected compared to a corestage diameter of approximately $17 \mathrm{~cm}$. Length and position of the sting had some influence as well, so the minimum length of $23 \mathrm{~cm}$ (pluming and wiring contraints) and the forward most position that would sufficiently support the model was chosen.

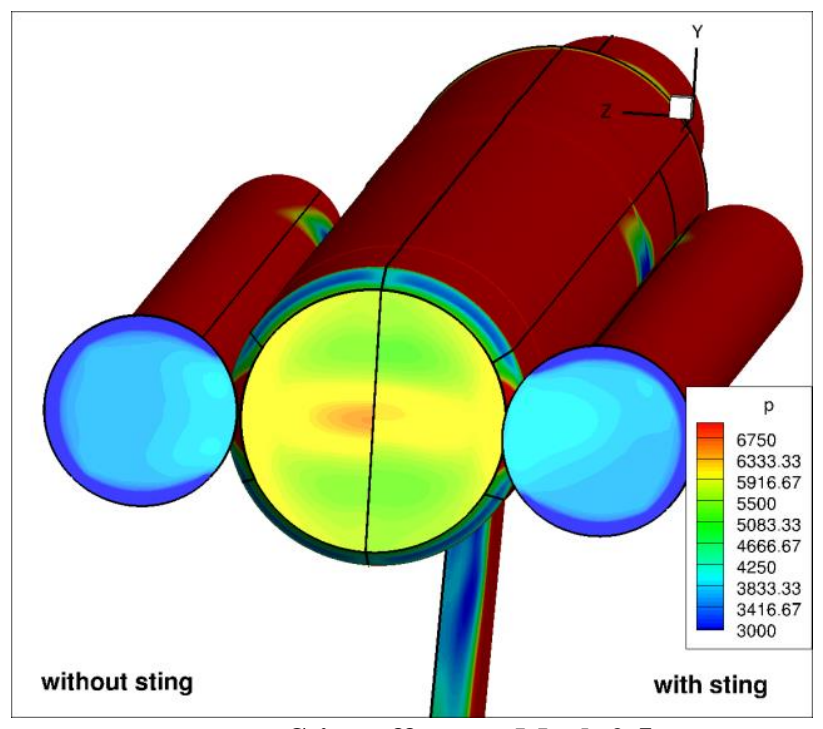

a. Sting effects at Mach 2.5

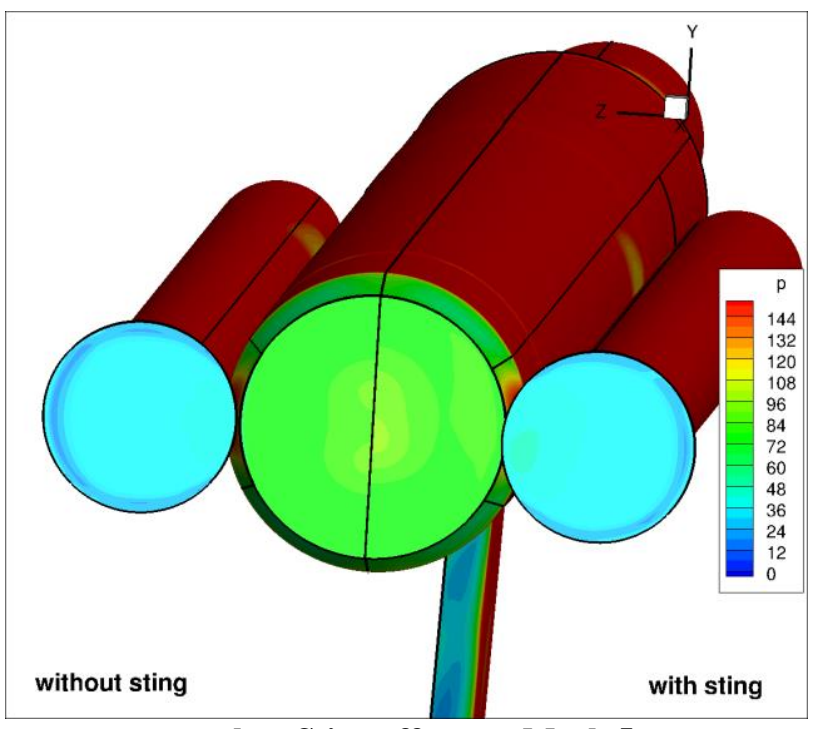

b. Sting effects at Mach 5

Figure 9. Plume Off Base Pressure Comparisons with and without Sting

\section{Conclusion}

In support of NASA's development efforts for the SLS vehicle, a sub-scale hot-fire model was developed for supersonic and hypersonic wind tunnel testing. A short-duration test technique is used similar to that used in Space Shuttle and Saturn base heating tests with several improvements noted. Rocket motor development, characterization testing, and performance analysis is reviewed showing steady core-stage engine pressures over 2,700 psi and steady solid rocket motor pressures over 700 psi. These operating pressures are nearly twice those achieved in the Space Shuttle base heating program. Additionally, the LENS II shock \& Ludwieg tube facility was utilized for testing at duplicated flight conditions from Mach 2.8-5.1. Previous base flow plume interaction studies have been done in cold flow facilities where freestream pressure, Mach number, or dynamic pressure could be matched, but not all simultaneously. Other improvements include development of an aerodynamic sting with minimal wake influence in the base region, and development of a tunable diode laser absorption spectroscopy gas temperature measurement. Detailed base heating environments will be reported in future work. Test methodology and test article engine/motor design is scalable to other pressures, constituents, and configurations.

\section{Acknowledgements}

This work is supported by NASA Marshall Space Flight Center under contract NNJ11HC71C.

\section{References}

1. Goethert, B. H. "Base Flow Characteristics of Missiles with Cluster-Rocket Exhausts," Institute of Aeronautical Sciences (IAS) Paper 60-89. 1960.

2. Mehta, M., Canabal, F., Tashakkor, S. B., and Smith, S. D. "Numerical Base Heating Sensitivity Study for a FourRocket Engine Core Configuration," Journal of Spacecraft and Rockets Vol. 50, No. 3, 2013, pp. 509-526.

3. Brewer, E. B., and Craven, C. E. "Experimental Investigation of Base Flow Field at High Altitude for a Four-Engine Clustered Nozzle Configuration." NASA Technical Note, TN D-5164, 1969.

4. Mullen, C. R., Bender, R. L., Bevill, R. L., Reardon, J., and Hartley, L. "Saturn Base Heating Handbook." The Boeing Company, NASA CR-61390, Huntsville, AL, 1972. 
5. Musial, N. T., and Ward, J. J. "Base Flow Characteristics for Several Four-Clustered Rocket Configurations at Mach Numbers from 2.0 to 3.5." NASA Technical Note, TN D-1093, 1961.

6. Pindzola, M. "Jet Simulation in Ground Test Facilities," AGARD-NATO Fluid Dynamics Panel. Paris, France, 1963.

7. Reig, J. L., Velazquez, A., and Rodriguez, M. "Quasi-Analytical Prediction of Base Flow-Plume Interaction," Proceedings of the Third European Symposium on Aerothermodynamics for Space Vehicles. Noordwijk, Netherlands, 1998.

8. $\quad$ Sergeant, R. J. "Base Heating Scaling Criteria for a Four-Engine Rocket Cluster Operating at High Altitude," AIAA Aerothermochemistry of Turbulent Flows Conference. San Diego, CA, AIAA 65-826, 1965.

9. Hendershot, K. C., Drzewiecki, R. F., and Lemoine, P. L. "Development of a Hot Rocket Subscale Space Shuttle Model for Base Flow Studies," AIAA/SAE 10th Propulsion Conference. SanDiego, CA, AIAA Paper No. 74-1147, 1974.

10. Sutton, G. P. Rocket Propulsion Elements, 3rd Ed. New York: John Wiley and Sons, Inc., 1963.

11. Wadhams, T. P., MacLean, M. G., and Holden, M. S. "Experimental Studies of Spherical Capsule Wake Flows with Reaction Control Jet Interaction," 52nd Aerospace Sciences Meeting. AIAA 2014-0510, 2014.

12. Mehta, M., Dufrene, A., Seaford, C. M., Kirchner, R. D., Solly, N., Vizcaino, J., and Kovarik, B. C. "Sub-Scale Space Launch System Core-Stage Rocket Engine Development for Short-Duration Testing," JANNAF Paper No. 3575, 46th Combustion /34th Airbreathing Propulsion / 34th Exhaust Plume and Signatures / 28th Propulsion Systems Hazards Joint Subcommittee Meeting. Albuquerque, NM, 2014.

13. Mehta, M., Dufrene, A., Solly, N., Seaford, C. M., and Kovarik, B. C. "Sub-Scale Space Launch System Solid Rocket Booster Develoment for Short-Duration Testing," JANNAF Paper no. 3576, 46th Combustion / 34th Airbreathing Propulsion / 34th Exhaust Plume and Signatures / 28th Propulsion Systems Hazards Joint Subcommittee Meeting. Albuquerque, NM, 2014.

14. Fuller, C. E., Powell, R. T., and Levie, J. K., III. "Diagnostic Evaluation Testing of a Gas Recovery Temperature Probe in the NASA/MSFC Impulse Base Flow Facility." NASA-CR-161500, Remtech, Inc., Huntsville, AL, 1978.

15. Fuller, C. E., W., M. M., Powell, R. T., and Levie, J. K., III. "Utilization of a Gas Temperature Recover Probe on Space Shuttle Short Duration Base Heating Model Tests OH-78 and IH-39." Interim Report M5M8XMS-483101M, Remtech, Inc., Huntsville, AL, 1977.

16. East, R. A., and Perry, J. H. "A Short Time response Stagnation Temperature Probe." Aeronautical Research Council, CP No. 909, 1967.

17. Buttsowrth, D. R., and Jones, T. V. "High Bandwidth Stagnation Temperature Measurements in a Mach 6 Gun Tunnel Flow," Experimental Thermal and Fluid Science Vol. 27, 2003, pp. 177-186.

18. Carr, Z., Parker, R., Dufrene, A., and Mehta, M. "Development of a TDLAS Instrument for Plume and Base Temperature Measurements of Sub-Scale Hot-Fire Rockets," JANNAF Paper No. 3736, 46th Combustion / 34th Airbreathing Propulsion / 34th Exhaust Plume and Signatures / 28th Propulsion Systems Hazards Joint Subcommittee Meeting. Albuquerque, NM, 2014.

19. Wright, M. J., Candler, G. V., and Bose, D. "Data-parallel line relaxation method for the Navier-Stokes equations," AIAA Journal Vol. 36, No. Copyright 1998, IEE, 1998, pp. 1603-9. 